\section{Vasopressor requirement during targeted temperature management for out-of-hospital cardiac arrest caused by acute myocardial infarction without cardiogenic shock}

Gyuho Song, Yeonho You, Wonjoon Jeong, Junwan Lee, Yongchul Cho, Seungwhan Lee, Seung Ryu, Jinwoong Lee, Seungwhan Kim, Insool Yoo

Department of Emergency Medicine, Chungnam National University Hospital, Chungnam National University College of Medicine, Daejeon, Korea

Objective We investigated whether patients with out-of-hospital cardiac arrest (OHCA) due to an acute myocardial infarction without cardiogenic shock required higher doses of vasopressors with low targeted temperature management (TM) after return of spontaneous circulation.

Methods We included consecutive comatose patients resuscitated from OHCA between January 2011 and December 2013. Patients with return of spontaneous circulation, regional wall motion abnormality on echocardiography, and coronary artery stenosis of $\geq 70 \%$ on percutaneous coronary artery angiography were enrolled. These patients received $36^{\circ} \mathrm{C} T \mathrm{M}$ or $33^{\circ} \mathrm{C}$ TM following approval of TMM by patients' next-of-kin $\left(36^{\circ} \mathrm{C}\right.$ and $33^{\circ} \mathrm{C}$ TM groups, respectively). The cumulative vasopressor index was compared between groups.

Results During induction phase, dose of vasopressors did not differ between groups. In the maintenance phase, the norepinephrine dose was $0.37 \pm 0.57$ and $0.26 \pm 0.91 \mu \mathrm{g} \cdot \mathrm{kg}^{-1} \cdot \mathrm{min}^{-1}$ in the $33^{\circ} \mathrm{C}$ and $36^{\circ} \mathrm{C} T \mathrm{M}$ groups, respectively $(\mathrm{P}<0.01)$. During the rewarming phase, the norepinephrine and dopamine doses were $0.49 \pm 0.60$ and $9.67 \pm 9.60 \mathrm{mcg} \cdot \mathrm{kg}^{-1} \cdot \mathrm{min}^{-1}$ in the $33^{\circ} \mathrm{C}$ TM group and $0.14 \pm 0.46$ and $3.13 \pm 7.19 \mathrm{mcg} \cdot \mathrm{kg}^{-1} \cdot \mathrm{min}^{-1}$ in the $36^{\circ} \mathrm{C}$ TM group, respectively $(\mathrm{P}<0.01)$. The median cumulative vasopressor index was 8 (interquartile range, 3 to 8 ) and 4 (interquartile range, 0 to 8$)$ in the $33^{\circ} \mathrm{C}$ and $36^{\circ} \mathrm{C}$ TM groups, respectively $(P=0.03)$.

Conclusion In this study, patients with OHCA due to acute myocardial infarction without cardiogenic shock had an elevated vasopressor requirement with $33^{\circ} \mathrm{C} T \mathrm{M}$ compared to $36^{\circ} \mathrm{C} T \mathrm{M}$ during the maintenance and rewarming phases.

Keywords Hypothermia; Myocardial infarction; Vasoconstrictor agents
elSSN: 2383-4625

Received: 12 November 2015 Revised: 2 February 2016

Accepted: 3 February 2016

Correspondence to: Yeonho You Department of Emergency Medicine, Chungnam National University Hospital, 282 Munhwa-ro, Jung-gu, Daejeon 35015, Korea

E-mail:yyo1003@naver.com

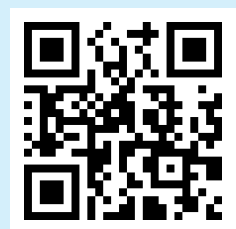

How to cite this article:

Song G, You Y, Jeong W, Lee J, Cho Y, Lee $S$, Ryu S, Lee J, Kim S, Yoo I. Vasopressor requirement during targeted temperature management for out-of-hospital cardiac arrest caused by acute myocardial infarction without cardiogenic shock. Clin Exp Emerg Med 2016;3(1):20-26.

This is an Open Access article distributed under the terms of the Creative Commons Attribution Non-Commercial License (http:// creativecommons.org/licenses/by-nc/3.0/). 


Capsule
Wummat is already known
Several studies have supported that targeted temperature management (TTM) is not associated with vasopressor re-
quirements. However, these studies investigated the relationship between TM and vasopressor requirements in the
management of out-of-hospital cardiac arrest with cardiogenic shock during the induction phase of TTM.
What is new in the current study
Patients with out-of-hospital cardiac arrest due to acute myocardial infarction who did not have cardiogenic shock im-
mediately after return of spontaneous circulation required a higher dose of vasopressors or inotropes during the main-
tenance and rewarming phases of TMM at 33 degrees C compared with TM at 36 degrees $C$.

\section{INTRODUCTION}

Coronary artery disease is the cause of up to $90 \%$ of out-of-hospital cardiac arrest (OHCA) cases, which is a leading cause of death in the developed world. ${ }^{1-3}$ Therefore, international guidelines recommend development of protocols to treat acute myocardial infarction (AMI) and establish coronary reperfusion, based on local requirements, in areas with frequent AMls. International guidelines also recommend the use of targeted temperature management (TTM) for treating OHCA in patients with primary ventricular fibrillation or ventricular tachycardia, and consideration of TM for other rhythms and for in-hospital cardiac arrests. ${ }^{4}$ However, hemodynamic instability is common in comatose OHCA survivors, because of post-cardiac arrest syndrome, and may be exacerbated by induction of TMM. ${ }^{5}$

Previous studies have suggested that systemic vascular resistance increases with $T \mathrm{M}$, while cardiac output decreases in parallel with the heart rate. ${ }^{6}$ However, other studies in patients with vasopressor-dependency after cardiac arrest showed that induction of TTM was not associated with a decrease in mean arterial pressure or increase in vasopressor requirement, and TTM was not associated with total cumulative vasopressor index (CVI), survival, or a good outcome. ${ }^{7.8}$ However, these studies investigated the relationship between TTM and vasopressor requirements in the management of OHCA with cardiogenic shock, in which vasopressors are needed to increase myocardial contractility. This fact led us to question whether or not OHCA due to AMI without cardiogenic shock requires vasopressors during TTM. Therefore, this study evaluated whether patients with OHCA due to AMI who did not have cardiogenic shock immediately after return of spontaneous circulation (ROSC) required higher doses of vasopressors or inotropes during TTM.

\section{METHODS}

\section{Study design and setting}

This was a prospective observational study, which included a cohort of consecutive comatose patients (Glasgow Coma Scale $\leq 8$ ), who were resuscitated from OHCA and admitted to the tertiary care center at a single hospital between January 2011 and December 2013. Our institutional review board approved the study protocol. Written informed consent was obtained from the nextof-kin of all patients.

\section{Participants}

Adults ( $\geq 18$ years) who presented to the emergency department of a single tertiary care center with OHCA were considered for enrollment. Patients with $\geq 70 \%$ coronary artery stenosis by angiography were designated as an AMI with a culprit lesion. ${ }^{9}$ We enrolled patients with sustained ROSC, regional wall motion abnormality on echocardiography, and $\geq 70 \%$ coronary artery stenosis by angiography. We excluded patients with the following: 1) a diagnosis of stroke, based on brain computed tomography, 2) a comatose state or terminal illness before OHCA, 3) asphyxia as the cause of the arrest, 4) systolic blood pressure $<90 \mathrm{mmHg}$ and a cardiac index of $<2.6 \mathrm{~L} \cdot \mathrm{min}^{-1} \cdot \mathrm{m}^{-2}$ immediately after ROSC, 5) body temperature $\leq 32^{\circ} \mathrm{C}$ immediately after ROSC, 6) normal coronary angiography immediately after ROSC, or 7) lack of consent from the next-of-kin for percutaneous coronary intervention. We used a Vigileo Monitor (Edwards Lifesciences Corporation, Irvine, CA, USA) to measure the cardiac index. We applied $36^{\circ} \mathrm{C}$ TM for patients whose next-of-kin did not approve of $33^{\circ} \mathrm{C}$ TTM (36 $6^{\circ} \mathrm{C}$ TTM group), or $33^{\circ} \mathrm{C}$ TTM for patients whose next-ofkin approved of this intervention ( $33^{\circ} \mathrm{C}$ TM group).

\section{Data sources and measurement}

In the $33^{\circ} \mathrm{C}$ TM group, TM was induced with intravenous rapid 
infusion of $20 \mathrm{~mL} / \mathrm{kg}$ of $4^{\circ} \mathrm{C}$ saline solution and by surface cooling with the Arctic Sun Temperature Management System (Medivance, Louisville, CO, USA). The target temperature was $33^{\circ} \mathrm{C}$; however, temperatures between $32^{\circ} \mathrm{C}$ and $34^{\circ} \mathrm{C}$ were permitted. The cooling duration was 12 hours after reaching $33^{\circ} \mathrm{C}$. Temperature was monitored in the esophagus and bladder. Subjects were rewarmed at a target rate of $0.25^{\circ} \mathrm{C} / \mathrm{hr}$. In the $36^{\circ} \mathrm{C}$ TTM group, surface cooling with the Medi-Therm II thermal regulating system (Gaymar Industries, Orchard Park, NY, USA) as a cooling blanket plus ice packs was used to attain a target temperature of $36^{\circ} \mathrm{C}$. Temperature was monitored in the rectum and tympanic membrane. Sedation with propofol or benzodiazepines was recommended to control shivering. Paralysis was intermittently employed during the induction of TMM. Fluid infusion and use of vasopressors and inotropes helped in achieving a urine output of $\geq 0.5 \mathrm{~mL} \cdot \mathrm{kg}^{-1} \cdot \mathrm{hr}^{-1}$ and a mean arterial pressure of $\geq 80 \mathrm{mmHg}$. The choice of specific vasopressors was based on the individual clinician's preference. The induction phase was defined as the first 8 hours following ROSC in the $36^{\circ} \mathrm{C}$ TM group and as the time necessary to attain a body temperature of $33^{\circ} \mathrm{C}$ following ROSC in the $33^{\circ} \mathrm{C} T \mathrm{M}$ group. The maintenance phase was defined as the 12 hours following the induction phase in both groups. The rewarming phase was defined as the time interval from when the maintenance phase was terminated until the target temperature of $36^{\circ} \mathrm{C}$ was reached in both groups. We measured the CVI as the primary outcome during TM in both groups. The CVI is a previously published scale based on potency and dose of vasopressors, which assigns points for equivalent doses of commonly used vasopressor agents, and quantifies the overall degree of vasopressor support. ${ }^{10,11}$

\section{Variables}

Data on age, sex, location of arrest, call-to-first cardiopulmonary resuscitation (CPR) attempt interval, call-to-ROSC interval, doorto-balloon time, cardiac output immediately after ROSC, in-hospital mortality, and initial cardiac rhythm at the time of OHCA were measured. We recorded vasopressor dose when it was changed, and cerebral performance category (CPC), core temperature, systolic arterial pressure, and diastolic arterial pressure every hour. To calculate the multiple organ dysfunction score (heart rate, central venous pressure, mean arterial pressure, fraction of inspired oxygen, partial pressure of oxygen, serum creatinine level, total bilirubin level, platelet count, and Glasgow Coma Scale), we recorded the data at a single constant time point (the first morning values) as recommended by Marshall et al. ${ }^{12}$

\section{Quantitative variables and statistical methods}

Continuous data are presented as mean values and standard de- viations or median values and interquartile ranges (IQR), according to the distribution of the data. Categorical data are presented as counts and proportions. All statistical analyses were performed using IBM SPSS Statistics ver. 19.0 (IBM, Armonk, NY, USA). We compared the two groups using an independent t-test, the MannWhitney test, and Fisher's exact test. Values of $\mathrm{P}<0.05$ were considered significant.

\section{RESULTS}

\section{General characteristics}

A total of 82 consecutive comatose patients with acute myocardial infarction as the cause of OHCA admitted to the hospital in the study period were treated with TTM (Fig. 1). The mean age of enrolled patients was $58.18 \pm 16.35$ years, the call-to-first CPR attempt interval was $13.04 \pm 6.39$ minutes, the call-to-ROSC interval was $47.87 \pm 17.20$ minutes, the door-to-balloon time was $36.07 \pm 6.92$ minutes, and the length of stay was $15.59 \pm 14.47$ days. The median multiple organ dysfunction score was 8 (IQR, 6 to 10), the median CVI was 4.5 (IOR, 0 to 8), and the mean cardiac output was $47.35 \pm 10.93 \%$. The mean time to attain a body temperature of $33^{\circ} \mathrm{C}$ following ROSC was $5.27 \pm 1.82$ hours. Other clinical characteristics of patients are summarized in Table 1.

The mean age was $64.29 \pm 14.00$ years in the $36^{\circ} \mathrm{C}$ TM group and $51.61 \pm 16.84$ years in the $33^{\circ} \mathrm{C}$ TM group $(P<0.01)$. The

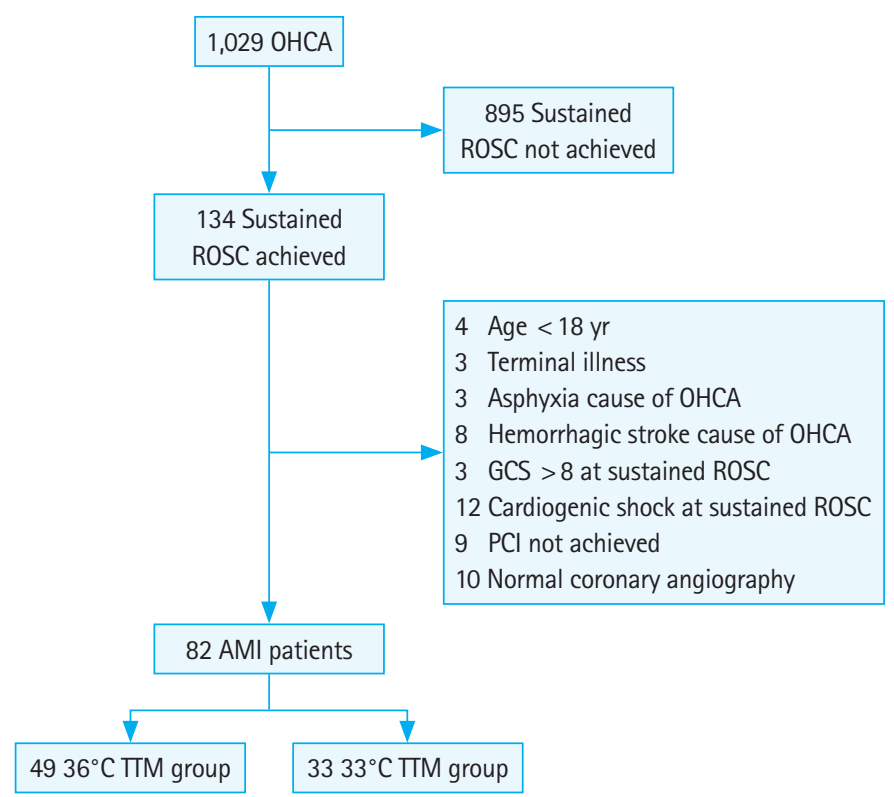

Fig. 1. Flow chart. The flow diagram shows patients admitted to a single hospital after out-of-hospital cardiac arrest (OHCA) from 2011 to 2013. ROSC, return of spontaneous circulation; GCS, Glasgow Coma Scale; $\mathrm{PCl}$, percutaneous coronary intervention; $\mathrm{AMI}$, acute myocardial infarction; TM, targeted temperature management. 
Table 1. General characteristics of study population

\begin{tabular}{llc}
\hline Contents & & Value \\
\hline Sex & Male & $70(85.4)$ \\
& Female & $12(14.6)$ \\
Target temperature management & $36^{\circ} \mathrm{C}$ & $49(59.8)$ \\
& $33^{\circ} \mathrm{C}$ & $33(40.2)$ \\
Age (yr) & & $58.18 \pm 16.35$ \\
Call-to-first CPR attempt interval (min) & $13.04 \pm 6.39$ \\
Call-to-ROSC interval (min) & $47.87 \pm 17.20$ \\
Door-to-balloon time (min) & $36.07 \pm 6.92$ \\
Length of stay (day) & $15.59 \pm 14.47$ \\
Cardiac output (\%) & $47.35 \pm 10.93$ \\
Time to attain a body temperature of $33^{\circ} \mathrm{C}$ following & $5.27 \pm 1.82$ \\
$\quad$ ROSC (hr) & \\
Multiple organ dysfunction score & $8(6-10)$ \\
Cumulative vasopressor index & $4.5(0-8)$
\end{tabular}

Values are presented as number (\%), mean \pm standard deviation, or median (interquartile range).

$\mathrm{CPR}$, cardiopulmonary resuscitation; ROSC, return of spontaneous circulation.

mean call-to-first CPR attempt interval was $12.33 \pm 4.51$ minutes in the $36^{\circ} \mathrm{C}$ TTM group and $14.09 \pm 8.43$ minutes in the $33^{\circ} \mathrm{C}$ TTM group $(P=0.70)$. The mean call-to-ROSC interval was $45.61 \pm 13.44$ minutes in the $36^{\circ} \mathrm{C}$ TM group and $51.21 \pm 21.41$ minutes in the $33^{\circ} \mathrm{C}$ TTM group $(\mathrm{P}=0.39)$. The mean door-to-balloon time was $35.98 \pm 6.15$ minutes in the $36^{\circ} \mathrm{C}$ TM group and $36.21 \pm 8.03$ minutes in the $33^{\circ} \mathrm{C} T \mathrm{M}$ group $(\mathrm{P}=0.63)$. The mean length of stay was $14.45 \pm 16.05$ days in the $36^{\circ} \mathrm{C}$ TTM group and $17.27 \pm$ 11.77 days in the $33^{\circ} \mathrm{C} T \mathrm{M}$ group $(\mathrm{P}=0.39)$. The median multiple organ dysfunction score was $8(I Q R, 5.5$ to 10.5$)$ in the $36^{\circ} \mathrm{C} T \mathrm{MM}$ group and $8(I Q R, 7$ to 10$)$ in the $33^{\circ} \mathrm{C} T M$ group $(P=0.87)$. The mean cardiac output was $46.38 \pm 10.23 \%$ in the $36^{\circ} \mathrm{C}$ TTM group, and $48.79 \pm 11.90 \%$ in the $33^{\circ} \mathrm{C}$ TTM group $(P=0.35)$. We compared CPC between the two groups. Of 49 patients included in the $36^{\circ} \mathrm{C}$ TTM group, $3(6.1 \%)$ had a CPC of 1, 7 (14.3\%) had a CPC of 3, 15 (30.6\%) had a CPC 4, and 24 (49.0\%) had a CPC 5. Of 33 patients included in the $33^{\circ} \mathrm{C}$ TM group, 10 (30.3\%) had a CPC 1, 5 (15.2\%) had a CPC 2, $9(27.3 \%)$ had a CPC 3, $3(9.1 \%)$ had a CPC 4, and $6(18.2 \%)$ had a CPC 5. CPC scores were better in the $33^{\circ} \mathrm{C}$ TM group than in the $36^{\circ} \mathrm{C}$ TM group $(P<0.01)$. The comparison of other clinical characteristics between the groups is summarized in Table 2.

\section{Comparison of arterial pressure between the $36^{\circ} \mathrm{C}$ and $33^{\circ} \mathrm{C}$ TTM groups}

The minimum arterial pressure was compared between the $36^{\circ} \mathrm{C}$ and $33^{\circ} \mathrm{C}$ TTM groups. In the induction phase, this value did not differ significantly between the groups. However, the minimum systolic arterial pressure and mean arterial pressure were lower in the $33^{\circ} \mathrm{C}$ TM group than in the $36^{\circ} \mathrm{C}$ TTM group in the mainte-
Table 2. Comparison of general characteristics between the $36^{\circ} \mathrm{C}$ and $33^{\circ} \mathrm{C}$ TTM groups

\begin{tabular}{llccc}
\hline Contents & Male & $\begin{array}{c}36^{\circ} \mathrm{C} T \mathrm{TM} \\
(\mathrm{n}=49)\end{array}$ & $\begin{array}{c}33^{\circ} \mathrm{C} T \mathrm{TM} \\
(\mathrm{n}=33)\end{array}$ & P-value \\
\hline Sex & Female & $7(85.7)$ & $28(84.8)$ & 0.91 \\
Survival rate of & Survived & $40(81.6)$ & $24(72.7)$ & 0.34 \\
patients & Died & $9(18.4)$ & $9(27.3)$ & \\
Cerebral perfor- & 1 & $3(6.1)$ & $10(30.3)$ & $<0.01$ \\
mance categories & 2 & $0(0.0)$ & $5(15.2)$ & \\
& 3 & $7(14.3)$ & $9(27.3)$ & \\
& 4 & $15(30.6)$ & $3(9.1)$ & \\
Initial heart rhythm & Asystole & $24(49.0)$ & $6(18.2)$ & \\
of arrest & PEA & $33(22.4)$ & $3(9.1)$ & 0.37 \\
& Pulseless VT & $2(4.1)$ & $1(3.0)$ & \\
Cardiac output & VF & $3(6.1)$ & $4(12.1)$ & \\
Multiple organ & & $46.38 \pm 10.23$ & $48.79 \pm 11.90$ & 0.35 \\
dysfunction score & & $8(5.5-10.5)$ & $8(7-10)$ & 0.87 \\
\hline
\end{tabular}

Values are presented as number (\%), mean \pm standard deviation, or median (interquartile range).

$\Pi \mathrm{M}$, targeted temperature management; PEA, pulseless electrical activity; $V T$, ventricular tachycardia; $\mathrm{VF}$, ventricular fibrillation.

Table 3. Comparison of arterial pressures between the $36^{\circ} \mathrm{C}$ and $33^{\circ} \mathrm{C}$ TTM groups

$36^{\circ} \mathrm{C}$ TM $(n=49) 33^{\circ} \mathrm{C}$ TTM $(\mathrm{n}=33)$ P-value

Induction phase $(\mathrm{mmHg})$

Minimum DAP

$87.45 \pm 19.83$

$90.70 \pm 16.37 \quad 0.30$

Minimum MAP

$48.94 \pm 12.09$

$49.73 \pm 12.71$

0.51

Maintenance phase $(\mathrm{mmHg})$

Minimum SAP

Minimum DAP

$63.03 \pm 14.05$

$64.02 \pm 12.40$

0.91

Minimum MAP

$98.06 \pm 13.01$

$86.94 \pm 18.93<0.01$

$54.96 \pm 9.72$

$50.91 \pm 16.01$

$<0.01$
0.05

Rewarming phase $(\mathrm{mmHg})$

Minimum SAP

$70.92 \pm 9.62$

$61.06 \pm 19.32$

$<0.01$

Minimum DAP

$98.35 \pm 20.01$

$92.09 \pm 16.18 \quad 0.02$

Minimum MAP

$56.12 \pm 13.56$

$53.36 \pm 14.52$

0.04

Values are presented as mean \pm standard deviation.

$\Pi \mathrm{M}$, targeted temperature management; SAP, systolic arterial pressure; DAP, diastolic arterial pressure; MAP, mean arterial pressure.

nance phase. The minimum systolic arterial pressure, diastolic pressure, and mean arterial pressure were lower in the $33^{\circ} \mathrm{C}$ TM group than in the $36^{\circ} \mathrm{C}$ TM group in the rewarming phase (Table 3 ). The arterial pressure and body temperature graphs of both groups are shown in Figs. 2 and 3.

\section{Comparison of vasopressor doses between the $36^{\circ} \mathrm{C}$ and $33^{\circ} \mathrm{C}$ TTM groups}

The median CVI was 4 (IQR, 0 to 8$)$ in the $36^{\circ} \mathrm{C}$ TM group and 8 (3 to 8) in the $33^{\circ} \mathrm{C}$ TM group $(P=0.03)$. In the induction phase, 
LEEM
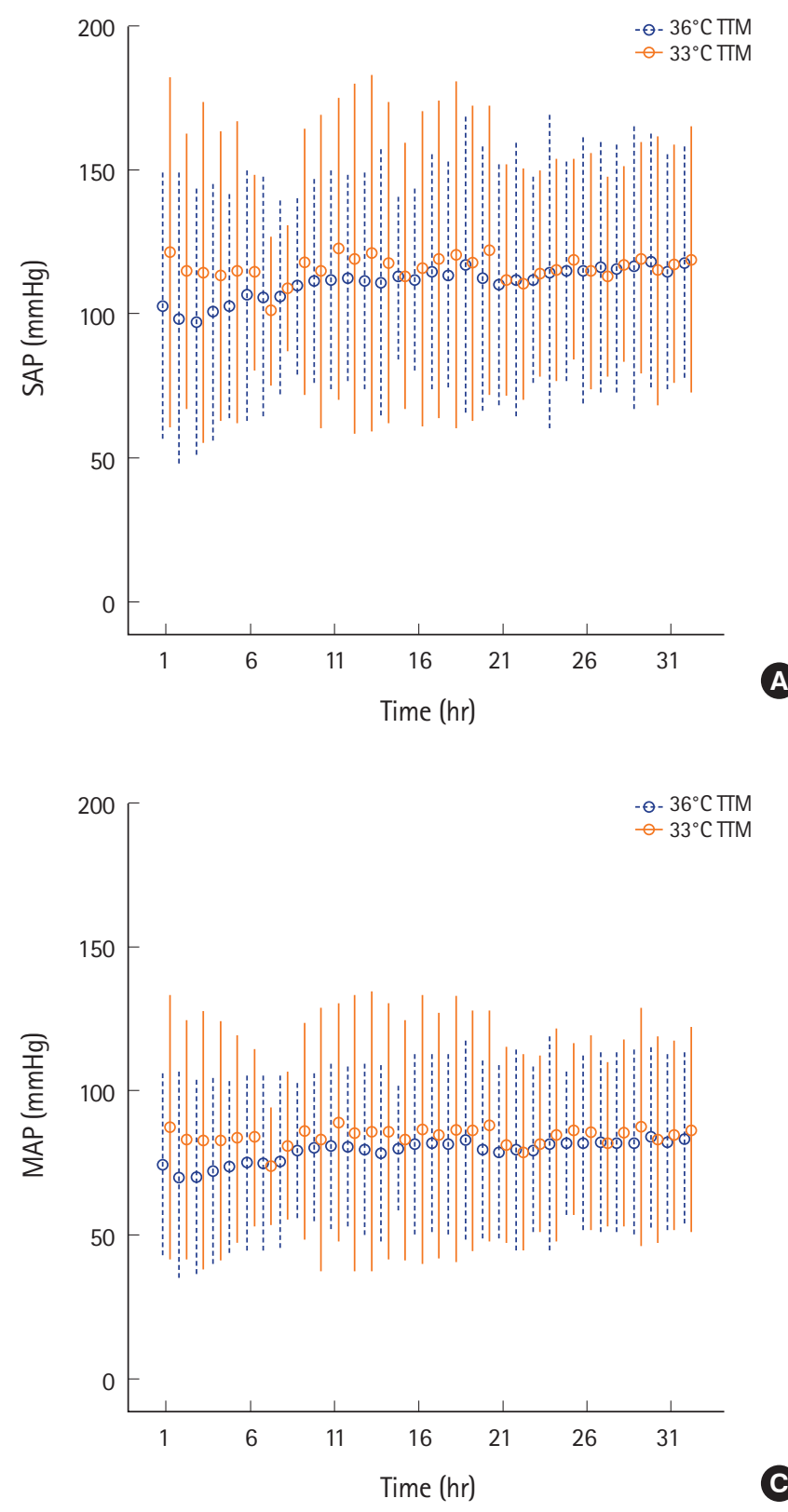

there were no significant differences in the dopamine, norepinephrine, epinephrine, and vasopressin doses between the groups. In the maintenance phase, patients in the $33^{\circ} \mathrm{C}$ TM group required higher doses of norepinephrine than did those in the $36^{\circ} \mathrm{C}$ TM group. In the rewarming phase, patients in the $33^{\circ} \mathrm{C}$ TM group required higher doses of dopamine and norepinephrine than did those in the $36^{\circ} \mathrm{C}$ TM group (Table 4).

\section{DISCUSSION}

In this study that excluded cardiogenic shock, the induction phase of TTM was not associated with a decrease in mean arterial pres-

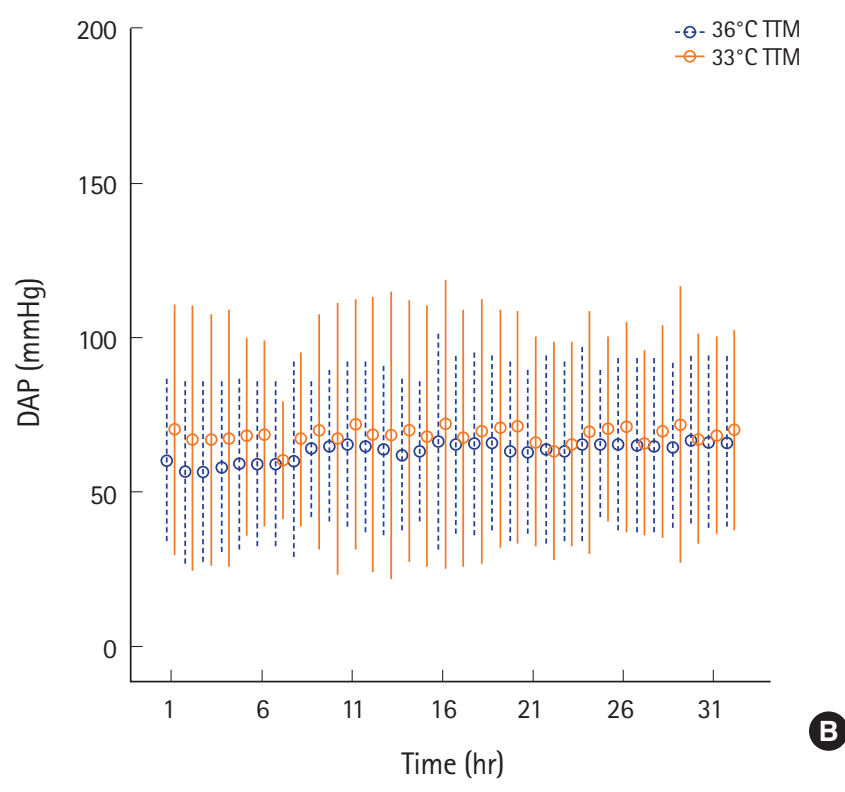

Fig. 2. These images show the arterial pressure in the $36^{\circ} \mathrm{C}$ and the $33^{\circ} \mathrm{C}$ targeted temperature management (TM) groups. Dashed lines represent interquartile range while circles represent median value. (A) systolic arterial pressure (SAP), (B) diastolic arterial pressure (DAP), and (C) mean arterial pressure (MAP). There were no significant differences of arterial pressure between groups during the induction phase. However, systolic arterial pressure and mean arterial pressure were lower in the $33^{\circ} \mathrm{C}$ TM group than in the $36^{\circ} \mathrm{C}$ TM group during the maintenance phase. Systolic arterial pressure, diastolic pressure and mean arterial pressure were lower in the $33^{\circ} \mathrm{C}$ TM group than in the $36^{\circ} \mathrm{C}$ TाM group in rewarming phase.

sure or increase in vasopressor requirement. Some studies in patients with vasopressor-dependency after cardiac arrest also showed that induction of TTM was not associated with decreased mean arterial pressure or increased vasopressor requirement, and TM was not associated with total $\mathrm{CVI}$, survival, or a good outcome. ${ }^{7,8}$

However, this study found a lower arterial pressure in the $33^{\circ} \mathrm{C}$ TTM group during the maintenance and rewarming phases. The $\mathrm{CVI}$ was also higher in the $33^{\circ} \mathrm{C}$ TM group. These findings suggest that the vasopressor requirement of the $33^{\circ} \mathrm{C}$ TM group was higher than that of the $36^{\circ} \mathrm{C} T \mathrm{M}$ group during the maintenance and rewarming phases. More than 50\% of patients develop late hemodynamic instability and vasodilation requiring administra- 


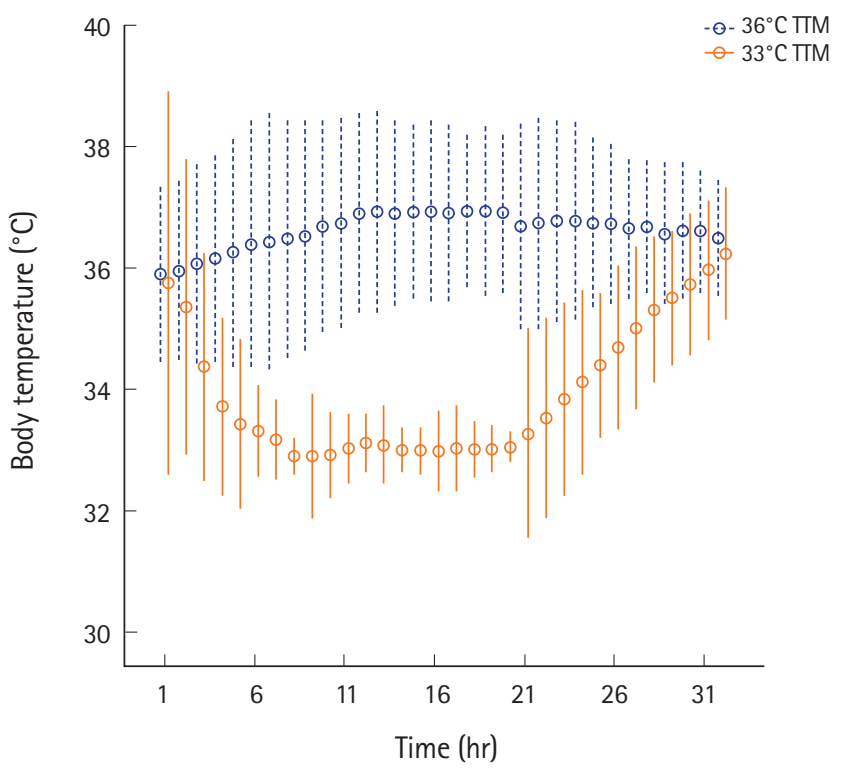

Fig. 3. These images show the mean core body temperature in the $36^{\circ} \mathrm{C}$ targeted temperature management (TM) and the $33^{\circ} \mathrm{C}$ TM groups. Dashed lines represent interquartile range while circles represent median value.

Table 4. Comparison of vasopressor doses between the $36^{\circ} \mathrm{C}$ and $33^{\circ} \mathrm{C}$ TाM groups

\begin{tabular}{|c|c|c|c|}
\hline Contents & $\begin{array}{c}36^{\circ} \mathrm{C} \text { ТTM } \\
(n=49)\end{array}$ & $\begin{array}{c}33^{\circ} \mathrm{C} \text { TाM } \\
(n=33)\end{array}$ & P-value \\
\hline Cumulative vasopressor index & $4(0-8)$ & $8(3-8)$ & 0.03 \\
\hline \multicolumn{4}{|l|}{ Whole phase } \\
\hline Dopamine $(\mathrm{mcg} / \mathrm{kg} / \mathrm{min})$ & $4.63 \pm 6.46$ & $7.68 \pm 7.59$ & 0.13 \\
\hline Norepinephrine (mcg/kg/min) & $0.20 \pm 0.55$ & $0.37 \pm 0.49$ & $<0.01$ \\
\hline Epinephrine (mcg/kg/min) & $0.02 \pm 0.09$ & $0.11 \pm 0.31$ & 0.56 \\
\hline Vasopressin (units/min) & $0.02 \pm 0.10$ & $0.04 \pm 0.23$ & 0.55 \\
\hline Dobutamine (mcg/kg/min) & $4.64 \pm 6.37$ & $6.72 \pm 6.96$ & 0.22 \\
\hline \multicolumn{4}{|l|}{ Induction phase } \\
\hline Dopamine $(\mathrm{mcg} / \mathrm{kg} / \mathrm{min})$ & $5.74 \pm 7.43$ & $3.15 \pm 5.98$ & 0.1 \\
\hline Norepinephrine (mcg/kg/min) & $0.18 \pm 0.26$ & $0.15 \pm 0.26$ & 0.58 \\
\hline Epinephrine (mcg/kg/min) & 0.0 & 0.0 & - \\
\hline Vasopressin (units/min) & 0.0 & 0.0 & - \\
\hline \multicolumn{4}{|l|}{ Maintenance phase } \\
\hline Dopamine $(\mathrm{mcg} / \mathrm{kg} / \mathrm{min})$ & $5.36 \pm 7.73$ & $8.11 \pm 8.21$ & 0.25 \\
\hline Norepinephrine $(\mathrm{mcg} / \mathrm{kg} / \mathrm{min})$ & $0.26 \pm 0.91$ & $0.37 \pm 0.57$ & 0.01 \\
\hline Epinephrine (mcg/kg/min) & $0.01 \pm 0.04$ & $0.04 \pm 0.20$ & 0.57 \\
\hline Vasopressin (units/min) & $0.02 \pm 0.11$ & $0.04 \pm 0.31$ & 0.76 \\
\hline \multicolumn{4}{|l|}{ Rewarming phase } \\
\hline Dopamine $(\mathrm{mcg} / \mathrm{kg} / \mathrm{min})$ & $3.13 \pm 7.19$ & $9.67 \pm 9.60$ & $<0.01$ \\
\hline Norepinephrine $(\mathrm{mcg} / \mathrm{kg} / \mathrm{min})$ & $0.14 \pm 0.46$ & $0.49 \pm 0.60$ & $<0.01$ \\
\hline Epinephrine $(\mathrm{mcg} / \mathrm{kg} / \mathrm{min})$ & $0.04 \pm 0.22$ & $0.25 \pm 0.81$ & 0.16 \\
\hline Vasopressin (units/min) & $0.04 \pm 0.17$ & $0.06 \pm 0.35$ & 0.54 \\
\hline \multicolumn{4}{|l|}{ Dose of dobutamine $(\mathrm{mcg} / \mathrm{kg} / \mathrm{min})$} \\
\hline Induction phase & $5.11 \pm 6.65$ & $2.76 \pm 5.08$ & 0.13 \\
\hline Maintenance phase & $5.61 \pm 7.86$ & $6.87 \pm 7.31$ & 0.41 \\
\hline Rewarming phase & $3.25 \pm 7.16$ & $8.37 \pm 9.00$ & $<0.01$ \\
\hline
\end{tabular}

Values are presented as median (interquartile ranges) or mean \pm standard deviation.

$\Pi \mathrm{M}$, targeted temperature management. tion of vasoactive drugs, and $33^{\circ} \mathrm{C}$ TM is associated with hemodynamic alterations, with decreased heart rate, elevated lactate levels, and need for increased vasopressor support compared with TTM at $36^{\circ} \mathrm{C}^{13-15}$

We assume that these differences resulted from peripheral vascular dilation and development of post-cardiac arrest syndrome during the maintenance and rewarming phases of $33^{\circ} \mathrm{C}$ TTM. Vasoactive agents are often needed to improve myocardial performance, to counteract vasodilation, and to maintain adequate organ perfusion, but may also cause tissue ischemia as an adverse event. ${ }^{16-18}$

This study had some limitations. First, the small sample size of the study could result in selection bias. Second, this study was limited to one center, and a larger study could have had different results. Third, our protocol did not mandate invasive hemodynamic monitoring (e.g., placement of a pulmonary artery catheter). Therefore, we did not evaluate the association between TM and changes in cardiac output directly.

This study of OHCA due to AMI without cardiogenic shock suggests that the vasopressor requirement increases during the maintenance and rewarming phases in patients treated with $33^{\circ} \mathrm{C}$ TM compared with $36^{\circ} \mathrm{C} T \mathrm{M}$, although $33^{\circ} \mathrm{C}$ TM delivery was not associated with an increased vasopressor requirement during induction.

\section{CONFLICT OF INTEREST}

No potential conflict of interest relevant to this article was reported.

\section{REFERENCES}

1. Zipes DP, Wellens HJ. Sudden cardiac death. Circulation 1998; 98:2334-51.

2. Dekker LR, Bezzina CR, Henriques JP, et al. Familial sudden death is an important risk factor for primary ventricular fibrillation: a case-control study in acute myocardial infarction patients. Circulation 2006;114:1140-5.

3. Reichenbach DD, Moss NS, Meyer E. Pathology of the heart in sudden cardiac death. Am J Cardiol 1977;39:865-72.

4. Peberdy MA, Callaway CW, Neumar RW, et al. Part 9: postcardiac arrest care. 2010 American Heart Association guidelines for cardiopulmonary resuscitation and emergency cardiovascular care. Circulation 2010;122(18 Suppl 3):S768-86.

5. Nolan JP, Neumar RW, Adrie C, et al. Post-cardiac arrest syndrome: epidemiology, pathophysiology, treatment, and prognostication. A Scientific Statement from the International Liaison Committee on Resuscitation; the American Heart Asso- 
ciation Emergency Cardiovascular Care Committee; the Council on Cardiovascular Surgery and Anesthesia; the Council on Cardiopulmonary, Perioperative, and Critical Care; the Council on Clinical Cardiology; the Council on Stroke. Resuscitation 2008;79:350-79.

6. Lewis ME, Al-Khalidi AH, Townend JN, Coote J, Bonser RS. The effects of hypothermia on human left ventricular contractile function during cardiac surgery. J Am Coll Cardiol 2002;39: 102-8.

7. Roberts BW, Kilgannon JH, Chansky ME, et al. Therapeutic hypothermia and vasopressor dependency after cardiac arrest. Resuscitation 2013;84:331-6.

8. Huynh N, Kloke J, Gu C, et al. The effect of hypothermia "dose" on vasopressor requirements and outcome after cardiac arrest. Resuscitation 2013;84:189-93.

9. Ambrose JA, Loures-Vale A, Javed U, Buhari CF, Aftab W. Angiographic correlates in type 1 and $2 \mathrm{Ml}$ by the universal definition. JACC Cardiovasc Imaging 2012;5:463-4.

10. Dhainaut JF, Antonelli M, Wright $P$, et al. Extended drotrecogin alfa (activated) treatment in patients with prolonged septic shock. Intensive Care Med 2009;35:1187-95.

11. Trzeciak S, McCoy JV, Phillip Dellinger R, et al. Early increases in microcirculatory perfusion during protocol-directed resuscitation are associated with reduced multi-organ failure at $24 \mathrm{~h}$ in patients with sepsis. Intensive Care Med 2008;34:2210-7.

12. Marshall JC, Cook DJ, Christou NV, Bernard GR, Sprung CL, Sibbald WJ. Multiple organ dysfunction score: a reliable de- scriptor of a complex clinical outcome. Crit Care Med 1995; 23:1638-52.

13. Bergman $R$, Braber $A$, Adriaanse $M A$, van Vugt $R$, Tjan $D H$, van Zanten AR. Haemodynamic consequences of mild therapeutic hypothermia after cardiac arrest. Eur J Anaesthesiol 2010;27: 383-7.

14. Laurent I, Monchi M, Chiche JD, et al. Reversible myocardial dysfunction in survivors of out-of-hospital cardiac arrest. J Am Coll Cardiol 2002;40:2110-6.

15. Bro-Jeppesen J, Annborn M, Hassager $C$, et al. Hemodynamics and vasopressor support during targeted temperature management at $33^{\circ} \mathrm{C}$ Versus $36^{\circ} \mathrm{C}$ after out-of-hospital cardiac arrest: a post hoc study of the target temperature management trial. Crit Care Med 2015;43:318-27.

16. Clutter WE, Bier DM, Shah SD, Cryer PE. Epinephrine plasma metabolic clearance rates and physiologic thresholds for metabolic and hemodynamic actions in man. J Clin Invest 1980; 66:94-101.

17. van den Broek MP, Groenendaal F, Egberts $A C$, Rademaker CM. Effects of hypothermia on pharmacokinetics and pharmacodynamics: a systematic review of preclinical and clinical studies. Clin Pharmacokinet 2010;49:277-94.

18. Tortorici MA, Kochanek PM, Poloyac SM. Effects of hypothermia on drug disposition, metabolism, and response: a focus of hypothermia-mediated alterations on the cytochrome P450 enzyme system. Crit Care Med 2007;35:2196-204. 